\title{
Analysis of Moodle Features to Build Moodle-Lite
}

\author{
Abdiansah ABDIANSAH ${ }^{1 *}$, and Alvi Syahrini UTAMI ${ }^{2}$ \\ ${ }^{1}$ AIRLab, Comp. Sci. Dept., Universitas Sriwijaya, Indonesia \\ ${ }^{2}$ AIRLab, Comp. Sci. Dept., Universitas Sriwijaya, Indonesia \\ *Corresponding author: abdiansah@unsri.ac.id
}

\begin{abstract}
Moodle is one of the LMS (Learning Management System) applications used to build E-Learning. Moodle is quite popular compared to other LMS because it provides several main advantages, namely free, feature rich and large community support. Even so, Moodle has some problems that are still being improved, like a userfriendly interface. This problem will be felt by ordinary users. In addition, the number of Moodle features both main features and additional features (plugins) causes Moodle's complexity to be even higher. In fact, sometimes users only use a number of features to help their work. Therefore, this study proposes a simple design of Moodle-Lite but more effective to the users. The basic foundation of Moodle-Lite design lies in two aspect, how often a feature is used and being talked by Moodle users. The first aspect is obtained by looking at the result in data survey from features that are often used. The second aspect is obtained through the analysis of a feature that is often discussed in Moodle Forum (MD). Furthermore, the best features obtained from both aspects will be made into Moodle-Lite features. The final results obtained six main features, namely: Quiz, Assignment, Feedback, Forum, Lesson, and Scorm.
\end{abstract}

\section{Keywords: Moodle, features, Moodle-Lite}

\section{Introduction}

The development of information technology has changed the learning and teaching process [1]. One of the IT products that is often used in education is e-learning. Today, e-learning is growing rapidly because it is supported by the concept "lifelong learning". Furthermore, ease of access in this digital era makes teaching and learning process easier. E-learning has several advantages that can overcome the weaknesses of conventional learning such as could eliminates geographical boundaries that affect many things such as financial problems, risks, and loss of time. E-learning also always adapts along with the alteration of the time and space and becoming more flexible [2]. One elearning's application that is quite popular is Moodle [3] because Moodle is an open source, rich in features and supported by very large community. Moodle offered many features that can be used by its users. But those features are not always have positive impact on users, especially lay users. furthermore, not all features are used by users. Unfortunately, there is no simple version from Moodle or Moodle-Lite which only uses features that are often used by users. Thus, to make Moodle become minimalistic, can be done by surveying over users and note down what features they often use. After that, based on the survey, Moodle-Lite can be made. There is an additional way beside using the survey, that is by analyze the results of the discussion in the forum that discuss Moodle. The results of the analysis will be used as an input to make Moodle-Lite.

Furthermore, this paper is organized as follows, Section 2 contain research that related to the analysis of Moodle features. Section 3 contain a brief description about Moodle. Section 4 contain research methodology that used. Section 5 contain the discussion and analysis results. Last section contain conclusion and future work.

\section{Related Works}

The research from [4] is main references and inspiration for this study. They analyzed Moodle's features based on the results of a survey of teachers from 30 universities. The survey they conducted was related to features that are often used. There are 16 features which are then divided into two, namely: (1) Twelves features related to learning activities; and (2) Four features related to learning resources. Measurement is done subjectively and qualitatively using a Qualitative Weight and Sum (QWS) approach. Their evaluation's result provide information that Moodle is often be used to provide lecture materials, schedule lectures, conduct assessments, create activities, gather lecture feedback and communicate between lecture participants. While the assignment features, quizzes and workshops are very rarely used.

\section{Research Method}

The collection of Moodle's features is done in two ways, namely: (1) Taking features derived from the survey results [4]. This method is a short way to obtain features without reducing the quality of the data. This is because these features have been studied scientifically and have been proven; and (2) Taking features from Moodle Forum (MD) by calculating how many threads and the number of the generated posts. 


\section{FEATURES ANALYSIS}

Moodle has four types of users, namely: admin, manager, teacher and student. Each user has a special feature. This study only discuss the main features that often interact with teacher and student. There are two modules that contain these features, namely the Activitiy module and Resources module. Table 1 provides features information which in both modules.

Table 1. Moodle features from Activity and Resources modules.

\begin{tabular}{|l|l|}
\hline \multicolumn{1}{|c|}{ Module } & \multicolumn{1}{c|}{ Features } \\
ACTIVITY & Assignment, Chat, Choice, Database, External tool, Feedback, Forum, \\
& Glossary, Lesson, Quiz, SCROM Package, Survey, Wiki, and Workshop \\
\hline RESOURCES & Book, File, Folder, IMS Content Package, Label, Page, and URL \\
\hline
\end{tabular}

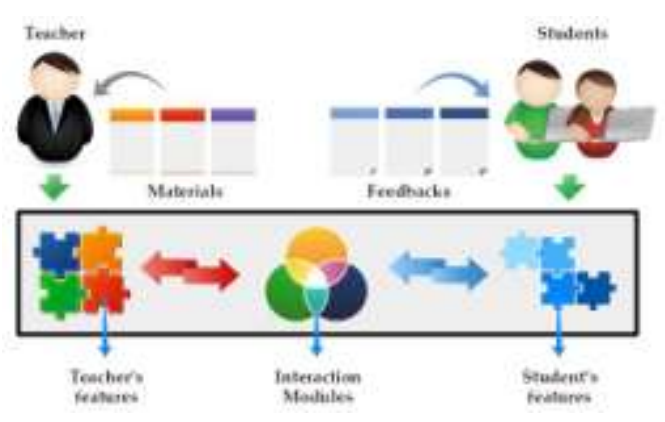

Figure 1. Proposed architecture for Moodle Lite.

\section{Proposed Architecture}

The results from the analysis in Moodle feature will be used as a reference to create Moodle- Lite. Design of Moodle-Lite architecture itself can be seen in Figure 1. Generally, there are five components that compose the architecture, namely: (1) Teacher as a supplier of material; (2) Students who provide feedback from the material provided; (3) Specific features for the teacher; (4) Features for students; and (5) Interaction Modules that contain modules as a bridge of interaction between teacher and student.

\section{RESULTS AND DISCUSSION}

\section{Results from Survey Data}

Table 2 and Table 3 are the results from the representation to the work done by [4]. In Table 2 there are 12 features for the module Activity with the percentage of usage. From these trials, information was obtained that there are 5 features that are often used, namely: Lesson, Quiz, Forum, Assignment, and Feedback. The most often used feature is the Feedback feature $96.66 \%$. While the feature that is rarely used is the Scorm feature of $46.66 \%$. Figure 2 provides a bar graph of the twelve features in Table 2. Percentages are sorted from lowest to highest. In the graph it can be seen that there are 5 features that have percentage above $80 \%$. Furthermore, these five features are considered the best features. 
Table 2. Moodle features usage from Activity module.

\begin{tabular}{|l|c|l|c|}
\hline \multicolumn{1}{|c|}{ Features } & Usage (\%) & \multicolumn{1}{|c|}{ Features } & Usage (\%) \\
\hline Assignment & 88,66 & Lesson & 83,33 \\
\hline Choice & 73,33 & Quiz & 83,33 \\
\hline Database & 70,00 & Scorm & 46,66 \\
\hline Feedback & 96,66 & & 66,66 \\
\hline Forum & & Survey & \\
\hline Glossary & 83,33 & & 73,33 \\
& & Wiki & 73,33 \\
\hline
\end{tabular}

Table 3 contains 6 features derived from the Resources module and accompanied by the percentage of its usage. The feature that most to be used is File, that is $100 \%$. While the features with rarely used are the Book, that is $76.66 \%$. In Figure 3 can be seen the representation of Table 3 into the bar graph. In the graph, it can be seen that there are 4 features with a percentage above $80 \%$, namely: Page, Folder, URL, and File. Therefore, these four features will be considered as the best features. Based on the previous data processing results, 9 features are considered to be frequently used by Moodle users, namely: Lesson, Quiz, Forum, Assignment, and Feedback, Page, Folder, URL, and File. Furthermore, all these features will be collaborated with features derived from MF analysis results.

Table 3. Moodle features usage from Resources module.

\begin{tabular}{|l|c|l|c|}
\hline \multicolumn{1}{|c|}{ Features } & Usage (\%) & Features & Usage (\%) \\
\hline Book & 76,66 & Label & 76,66 \\
\hline File & 100 & Page & 90 \\
\hline Folder & 90,00 & URL & 93,33 \\
\hline
\end{tabular}


Figure 4 gives a graph about all the total posts in every

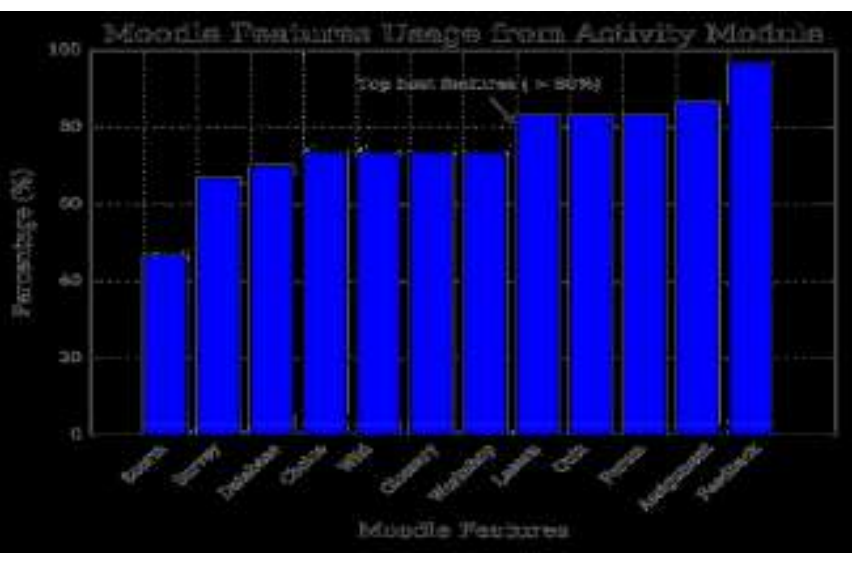

Figure 2. Moodle features usage from Activity Module.

\section{Results from Moodle Forum (MF) Analysis}

Moodle Forum (MF) will display 100 threads for each display and sorted by the active time of the thread. In a while, we only count the number of posts on the first page and assume that the other pages have similar number of posts. We thread to be like this because we want to see in general about the features that are being actively discussed. Based on the Table 4 it can be seen that MF is quite active with a total number of threads is 368 , total posts is 3,942 , so the amount for all is 114,177 . The data is enough to prove that Moodle is strongly supported by the user community. feature sorted in ascending. In the graph, it can be seen that the feature with the most total post is the Quiz feature (53.856) while the least is the Survey feature (306). Thus can be obtained three features with the gratest total posts (above 10,000), namely: Assignment, SCORM, and Quiz. If this result is sliced with the previous survey results, then the Assignment and Quiz features are included in features that are often used and discussed by Moodle users. Interestingly, from these two results there are two contradictory features, namely Feedback and SCORM.

\section{CONCLUSION AND FUTURE WORKS}

This article is about analyzing Moodle features that are often used and discussed by Moodle users. Moodle provides many features but not all features are used by users. Therefore, this study proposes a simple and effective version of the Moodle design called MoodleLite. The beginning stage of Moodle-Lite design is to evaluate the features that often be used and discussed by Moodle users. Those both aspects become the basic foundation to build Moodle-Lite. The first aspect is obtained by looking at the survey features that often used by [4]. While the second aspect is obtained by analyzing how often these features are discussed at MF. From these two aspects we can.

show that the best six features to be used as Moodle-Lite features, namely: Quiz, Assignment, Feedback, Forum, Lesson, and SCORM. 
Table 4. Moodle features usage from Activity module.

\begin{tabular}{|c|c|c|c|}
\hline Features & Sum of Thread & Sum of Post & Total \\
\hline Assignment & 41 & 244 & 10.004 \\
\hline Book & 7 & 303 & 2.121 \\
\hline Chat & 7 & 149 & 1.043 \\
\hline Choice & 3 & 229 & 687 \\
\hline Database & 14 & 390 & 5.460 \\
\hline Feedback & 8 & 187 & 1.496 \\
\hline Forum & 39 & 151 & 5.889 \\
\hline Glossary & 10 & 278 & 2.780 \\
\hline Lesson & 20 & 249 & 4.980 \\
\hline Quiz & 135 & 399 & 53.865 \\
\hline SCORM & 43 & 339 & 14.577 \\
\hline Survey & 2 & 153 & 306 \\
\hline Wiki & 15 & 271 & 4.065 \\
\hline Workshop & 8 & 337 & 2.696 \\
\hline Resources Types & 16 & 263 & 4.208 \\
\hline
\end{tabular}

Show that the best six features to be used as Moodle-Lite features, namely: Quiz, Assignment, Feedback, Forum, Lesson, and SCORM. 


\section{REFERENCES}

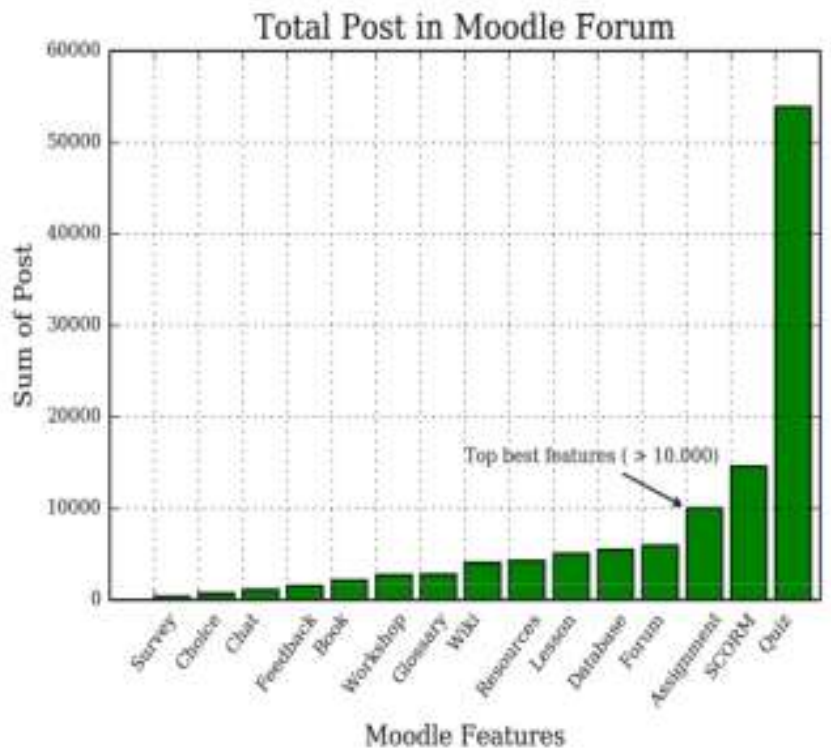

Figure 3. Total post of features in Moodle Forum.

The next research will make Moodle-Lite which contains this six features. Moodle's weaknesses related to the user interface will be solved using Responsive Web Design (RWD) technology so that the Moodle-Lite display will be user-friendly.
[1] Aristovnik, A. 2012. The impact of ICT on educational performance and its efficiency in selected EU and OECD countries: a nonparametric analysis.

[2] Cole, R. A. (2000). Issues in Web-based pedagogy: A critical primer. Greenwood Publishing Group.

[3] Amir, S. 2018. Moodle, https://tekno.kompas.com//moodle.portal.elearning.

[4] Depaak, K. C. 2017. Evaluation of Moodle Features at Kajaani University of Applied SciencesCase Study. Procedia computer science, 116, 121-128.

[5] Waheed, M., Kaur, K., Ain, N., \& Hussain, N. (2016). Perceived learning outcomes from Moodle: An empirical study of intrinsic and extrinsic motivating factors. Information Development, 32(4), 1001-1013.

[6] Gergen, K. J., \& Wortham, S. (2001). Social construction and pedagogical practice. Social construction in context, 115-136.

[7] Moodle. 2018, Moodle's Philosophy. MOODLE https://docs.moodle.org/35/en/Philosophy. 